\title{
Smart indicators to support the learning interaction cycle
}

\author{
Citation for published version (APA):
}

Glahn, C., Specht, M., \& Koper, R. (2008). Smart indicators to support the learning interaction cycle. International Journal of Continuing Engineering Education and Life-Long Learning, 18(1), 98-117. https://doi.org/10.1504/IJCEELL.2008.016078

\section{DOI:}

10.1504/IJCEELL.2008.016078

Document status and date:

Published: 01/01/2008

Document Version:

Publisher's PDF, also known as Version of record

Please check the document version of this publication:

- A submitted manuscript is the version of the article upon submission and before peer-review. There can be important differences between the submitted version and the official published version of record. People interested in the research are advised to contact the author for the final version of the publication, or visit the DOI to the publisher's website.

- The final author version and the galley proof are versions of the publication after peer review.

- The final published version features the final layout of the paper including the volume, issue and page numbers.

Link to publication

\section{General rights}

Copyright and moral rights for the publications made accessible in the public portal are retained by the authors and/or other copyright owners and it is a condition of accessing publications that users recognise and abide by the legal requirements associated with these rights.

- Users may download and print one copy of any publication from the public portal for the purpose of private study or research.

- You may not further distribute the material or use it for any profit-making activity or commercial gain

- You may freely distribute the URL identifying the publication in the public portal.

If the publication is distributed under the terms of Article 25fa of the Dutch Copyright Act, indicated by the "Taverne" license above, please follow below link for the End User Agreement:

https://www.ou.nl/taverne-agreement

Take down policy

If you believe that this document breaches copyright please contact us at:

pure-support@ou.nl

providing details and we will investigate your claim.

Downloaded from https://research.ou.nl/ on date: 26 Apr. 2023 


\title{
Smart Indicators to Support the Learning Interaction Cycle
}

\author{
Christian Glahn*, Marcus Specht, and \\ Rob Koper
}

Educational Technology Expertise Centre, Open University of the Netherlands, Valkenburger Weg 177, 6411AT Heerlen, The Netherlands

E-mail: christian.glahn@ou.nl_E-mail: marcus.specht@ou.nl

E-mail: rob.koper@ou.nl

*Corresponding author

\begin{abstract}
This paper focuses on the relevant information for collecting and presenting contextual information, its effects and impact on the learning interaction cycle, and mechanisms of controlling it. The core principle of the learning interaction cycle is the interaction of learners with their learning environment. Previous research highlights that such interaction is important for the experience and progress of learners. However, we identified a conceptual gap between the learner actions within a learning environment and the responses that are provided to the learners. To bridge this gap we adopted a layered model of context-aware systems that meets the requirements for supportive responses. The model has four layers and describes the information processing of interaction footprints of learners in a learning environment: The sensor layer, the semantic layer, the control layer, and the indicator layer. We applied this model to analyse the results as they were reported in the literature.
\end{abstract}

Keywords: learner support; interactive systems; learner monitoring; information visualisation; adaptive systems.

Reference to this paper should be made as follows: Glahn, C., Specht, M., and Koper, R. (2007) 'Smart indicators to support the learning interaction cycle', Int. J. Cont. Engineering Education and Lifelong Learning, Vol. \#, No. \#, pp \#.

Biographical notes: Christian Glahn is a PhD student at the Open University of the Netherlands. He studied educational- and computer-science at the Freie Universität Berlin and the University of Innsbruck, where he obtained his masters degree in media education in 2002. His research interests are smart and adaptive learning systems, web technologies, and their application in nonformal and informal learning. He contributes to open source software development and supports the technological enhancement and quality assurance of the online services within the Partnership Programme on Youth of the European Commission and the Council of Europe.

Dr. Marcus Specht is an Associated Professor at Open University of the Netherlands. He received his Diploma in Psychology in 1995 and a Dissertation from the University of Trier in 1998 on adaptive learning technology. His main research interests are adaptive learning and training systems, knowledge management, contextualised computing, and intelligent interfaces. He coordinated the technical development of a highly scalable e-Learning platform for design and architecture in the European WINDS project and was involved in the LISTEN project on audio augmented environments. Currently he is the 
C. Glahn, Specht, M., and Koper, R.

coordinator of the European project RAFT on field trip support for mobile collaboration and the work package coordinator for personalised learning tools in the European Network of excellence PROLEARN.

Prof. Dr. Rob Koper holds a PhD in educational technology from the Open University of the Netherlands. Since 1998 he has been a full professor in educational technology, specifically in e-learning technologies. As director of RTD into learning technologies he was, among other things, responsible for the development of Educational Modelling Language (the predecessor of IMS Learning Design). He led the OUNL's contribution to the IMS LD specification activities. His research focuses on self-organised distributed learning networks for lifelong learning, including RTD into software agents, educational semantic web, interoperability specifications and standards.

\section{Introduction}

Indicators are mechanisms to provide simplified information that are valuable to a task. With some background knowledge we can understand the meaning of an indicator without the need of knowing about the details of the underlying process or mechanism. For instance, the fuel needle of a car is an indicator. Whoever is familiar with driving cars knows that the fuel needle indicates how much fuel is left in the tank and that it is useful to check it regularly, if one wants to keep driving instead of walking. We understand that it is necessary to find a filling station if the fuel needle points towards the lower end of the scale. However, to make the appropriate decision it is not necessary to know the size of the fuel tank, the exact amount of fuel that is left in it, or about the fuel consumption of the motor. Some cars switch on an additional light, if the fuel level falls below a critical level. Such indicators focus our attention on important facts that we would miss or ignore otherwise. The telephone bell is another example for such indicators: It indicates that someone is calling on the phone. Without it we would not be aware of the incoming call, unless we were checking the telephone line actively. This leads to another characteristic of indicators: They help us focus on relevant information when it is required, while we do not have to bother about it most of the time.

This article is a review on current approaches of using indicators to support the learning interaction cycle. The learning interaction cycle addresses the interaction between a learner and a learning environment as the core of the learning process. Providing contextual information via indicators has been proven as important to support the learning process. Contextual information stimulates the learners' engagement in and commitment to the learning process (Beenen et al., 2004; Ling et al., 2005; Rashid et al., 2006); helps to raise awareness of and stimulates reflection about acquired competences (Kreijns, 2004; Kreijns \& Kirschner, 2002); and support thoughtful behaviour in navigation and on learning paths (Van Nimwegen, Van Oostendorp, Burgos, \& Koper, 2006). We analyse different approaches of using indicators to support the learning interaction cycle.

This paper focuses on the relevant information for collecting and presenting contextual information, its effects and impact on the learning interaction cycle, and mechanisms of controlling it. In other words, we analyse variables and concepts that make indicators on the learning process 'smart'. The objective is to enrich learning 
experiences in informal and non-formal learning environments, such as on-line communities of practice. Indicators of contextual information show effects and progress of the ongoing learning process where it otherwise would be hidden to the learner.

In the next section we illustrate the problems and the underlying concepts with a hypothetical scenario for an application of context-aware indicators. Based on this scenario we elaborate our view on the learning interaction cycle by developing a layered model for smart indicators. This model is based and validated on educational requirements. Later we use it to analyse the existing research, in which we focus on the approaches of collecting data from the learners, as well as aggregating and indicating information back to them. Before we conclude we investigate the effects of indicators for the learning process as they have been reported in the literature and derive some questions for further research from these results.

\section{The hypothetical scenario of Tim, the accountant}

For the last eight years Tim is working as an accountant in a small company specialised in the production of medical instruments. He considers his job as boring, but since Tim and his wife have bought a small house he depends on his job.

Recently, a new ERP system has been installed by his company and Tim has received an introductory seminar to the new environment. Unfortunately, he has no fellow colleagues to exchange and discuss about the new system, but he feels that he could do a better job if he would have a better understanding of how to use the different modules, components and interfaces of the new software. After hours of browsing the web searching for information, he subscribed to an on-line community in which problems, news and best practices about the ERP system are presented and discussed.

As Tim logs in the first time he recognises that the community portal provides an 'activity' widget. The widget displays the number of pages and forum postings Tim has accessed while he is clicking through the community's web-site. The widget shows a bar chart, in which a coloured bar grows a bit with each link that Tim follows. Tim receives more detailed information about his activity when he clicks on the widget, such as history of pages he has visited.

At his fifth visit to the community portal, Tim receives a message that he now has passed the starter phase and asks Tim if he likes the widget to display his activity level in relation to the rest of the community. Tim likes this idea and activates the new function.

The new widget has three components: First it shows the number of actions Tim has performed today at the community portal. These actions include downloads of documents, reading of postings at the community's discussion forum and contributions to forums and Wiki pages. Second, it indicates the average number of actions that were performed today. Third, it shows Tim's average number of actions that he has performed during the visits of the last four weeks. Now Tim can see that he is accessing more information than the average community member.

An additional bar chart appears in the widget after some time. This second bar chart has the label 'effort'. It has a similar set up like the one Tim is already familiar with. The chart shows the relation of the time Tim spends reading information and the size of that information. Like the first bar-chart, it has also two additional markers: One shows the same value for the community, the other one displays the value for the last four weeks.

When Tim investigates the two charts he sees that his activity level is quite high, but 
the effort appears to be quite low. Tim wonders about this and understands that he was flipping through the information most of the time, but did not read thoroughly. He decided to focus a bit more on the examples and relate them to his daily tasks in the office. Throughout the next sessions Tim realises that he develops a better understanding of the ERP system, while his effort bar and activity bar align to each other.

Over the time Tim starts to contribute regularly to the community's forum and Wiki pages. He sees that his activity widget started to display a third bar chart. This bar chart reports on the rates of his contributions that are accessed by other users. He sees that his contributions get high access rates and he is satisfied that he could provide useful information back to the community.

One day Tim visits the community portal and sees a new marker on the third chart about his contributions in the activity widget. This marker has the shape of a star. He becomes curious what it could mean and checks his report in more detail. The information shows that some of his contributions were highly rated for being helpful by other members of the community. Finally, Tim starts to understand that he developed some expertise in mastering the ERP system - and that his knowledge is also valuable for his job.

\section{The learning interaction cycle}

The scenario refers to principals of what Schön (1983) calls a "reflective practitioner" in a self-organised learning situation. Schön's theory states that reflection on practices is a core principle for competence development in the professions (Schön, 1983, 1987). In the scenario, Tim's awareness and reflection about his learning process is triggered by system generated information about his learning activities and those of his peers.

The learning interaction cycle describes the underlying model for system support of a learner's reflection, where the support is based on the learner's activities and context. The concept of learning interaction cycles addresses learning interactions as the core of the learning process.

A single interaction is defined by two parts: an action performed by a learner and a response to this action from the environment. Garries, Ahlers, \& Driskel (2002) define a learning interaction cycle by single interactions that are connected through the interpretation of a system response by the learner. At this level a learning process can be described as a chain of interactions between a learner and a corresponding environment. In that sense learning interaction cycles are microscopic views on learning processes.

However, this definition of the learning interaction cycle is limited as it focuses on the learner's cognitive processes and treats the system's side as a block box (Butler \& Winne, 1995; Garries, Ahlers, \& Driskel, 2002). Indicators are part of the interface of a system. In order to provide smart indicators the system cannot be simplified as a black box. Following concepts of context aware systems (Dey, 2000; Dey, Abowd, \& Salber, 1999; Zimmermann, Specht, \& Lorenz, 2005) interaction appears as a symmetrical process between an actor and a system that is interconnected by the system's interface (see Figure 1): Each action of an actor on the interface is analysed and assessed by the system. Based on this analysis the system provides a response to the action on the interface. The actor analyses and reflects on this response to judge the results of the initial action. Further actions depend on the outcomes of this last phase (Beck \& Wade, 2004; Garries, Ahlers, \& Driskel, 2002). 
Figure 1 Outline of the learning interaction cycle

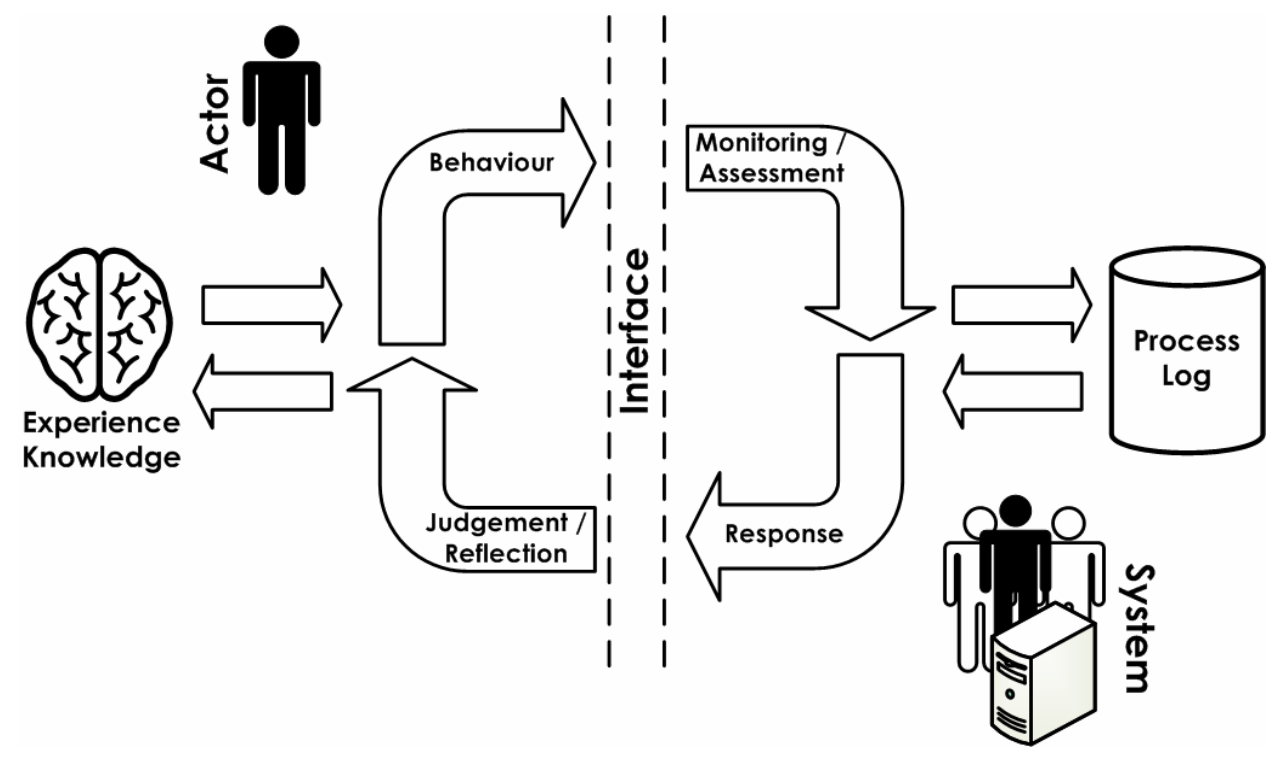

Schön's (1983) concept of reflection in action highlights also the relation of past experiences and the current situation of a practitioner. In terms of the learning interaction cycle we translate this to utilizing the interaction history to support learners while they are active in a learning environment. Wexelblat \& Maes (1999) define interaction history as traces of interactions between users and objects. The author argues that interaction history is extensively used by users to guide actions, to make choices, and to find things of importance or interest (Wexelblat \& Maes, 1999). Dron, Boyne, \& Mitchell (2001) use footprint to indicate the value and meaning of each interaction to the interaction history of an object in a social space. The authors introduce the term stigmergy to describe the role of footprints for emerging social spaces. This concept was already applied for the support of social navigation (Dieberger, 1997). Recently, Farzan \& Brusilovsky (2005) use the term interaction footprint to refer to different traces that are left during the interaction process. Such traces can be a note about accessing a document in a repository, or the time a learner spent reading a document (Farzan \& Brusilovsky, 2005).

It is a fundamental insight for this research that humans actively search for relations to their previous interactions, in particular for indicators that provide information on the success and value of their interactions. This is especially the case if the actions are based on strategies that require alignment during the process (Jamieson-Noel, Chu, \& Winne, 2004; Weber, 2003). In other words, learners continuously seek for indicators that help them to verify or modify their learning strategy.

When seen isolated, most interaction footprints are of little or no direct value to a learner. As shown in Tim's case, it is the higher level information or combinations of information that triggers his awareness and reflection. In the scenario the higher level information is information about learning activity within the community.

The scenario shows that the possible indicators depend on the learner's history within the learning environment: Certain information can be useful during early phases while the same information is of less value to the learner in later stages of the learning process. In 
the beginning, Tim receives information that is deduced from his activity in the community system. The provided information evolves while more interaction footprints become available. For Tim it makes no sense to receive information about peer ratings on his contributions if he has nothing contributed; but if this information becomes available it can be of higher value to Tim than his access rate of the learning material.

\section{Requirements for smart indicators}

In order to provide smart indicators for learner support in the learning interaction, it is necessary to develop an understanding about general principles of this process. These principles are the foundation of the core requirements for smart indicators.

From research on feedback and self-regulated learning (Butler \& Winne, 1995; Ley \& Young, 2001; Mory, 2003; Orange, 1999) we have learned that external feedback is important for the learning process. According to Ley \& Young (2001) it relies on three general principles:

- External feedback relies on monitoring of the learning actions and the learning context.

- External feedback has to adapt according to a learner's goals, actions, performance, outcomes and history.

- External feedback is a response to a learner's actions, which it is not necessarily immediate.

These principles are relevant to this research for two reasons: First, external feedback is a special kind of response within the learning interaction cycle (Butler \& Winne, 1995; Mory, 2003). Second, this research addresses learning in the professions and in particular learning in open environments such as communities of practice, as the scenario already illustrates. Considering general principles of self-regulated learning is reasonable for the support of learning interactions in such contexts, because adult learners commonly demand more control on their learning activities (Illeris, 2003).

The principles of Ley \& Young (2001) focus on the effects of responses on the learner. However, they do not consider the way of presenting this information to the learners. This is partly due to the fact, that they are based on the results from research on self-regulated learning or feedback. The research focuses largely on cognitive processes of the learner. Generating and communicating responses to the learner is usually beyond the scope of such research. However, in terms of the learning interaction cycle, indicating information to a learner is a critical factor (Dey \& Abowd, 2000; Kreijns, 2004).

Besides the information that relates directly to the user, several authors (Dieberger, 1997; Dron, Boyne, \& Mitchell, 2001; Farzan \& Brusilovsky, 2005; Kreijns, 2004) stress the relevance of contextual parameters on the learning process. Being informed on the social, spatial and logical context helps learners to select activities and assess the results of their actions.

To reflect indicators and context explicitly, we propose an extension of Ley \& Young's principles:

- External feedback relies on monitoring of the learning actions and the learning context. 
- External feedback has to adapt according to a learners’ goals, actions, performance, outcomes, and history as well as to the context in which the learning takes place.

- External feedback is an indicator that responds to a learner's actions or to changes in the context of the learning process, where the response is not necessarily immediate.

\section{Analytical model}

Different to research on self-regulated learning or feedback, our research addresses the system's side of the learning interaction cycle. Therefore, the analytical model of our research describes information processing from sensors to indicators, rather than the cognitive processes of the learner. In this study, the analytical model is derived from concepts of context-aware systems (Dey, 2000; Dey, Abowd, \& Salber, 1999; Zimmermann, Specht, \& Lorenz, 2005). Dey (2000) defines context as follows:

\footnotetext{
"Context is any information that can be used to characterise the situation of an entity. An entity is a person, place, or object that is considered relevant to the interaction between a user and an application, including the user and applications themselves.” (Dey, 2001, p. 5)
}

Dey and his colleagues (1999) describe an architecture for context-awareness that contains widgets, aggregators and interpreters. Widgets serve as interfaces for in- and output. The aggregators act "as a gateway between applications and elementary widgets and hide [...] complexity about the context sensing mechanism” (Dey, 2000, p. 80). Context interpreters analyse low-level information in order to identify and adapt to the context.

Zimmermann, Specht, \& Lorenz (2005) extend this architecture towards a more operational framework model for context-aware applications. The model describes operations on the data and information flow through a system from user input to system response, and has four layers (see Figure 2).

Figure 2 Layers for context-aware information processing

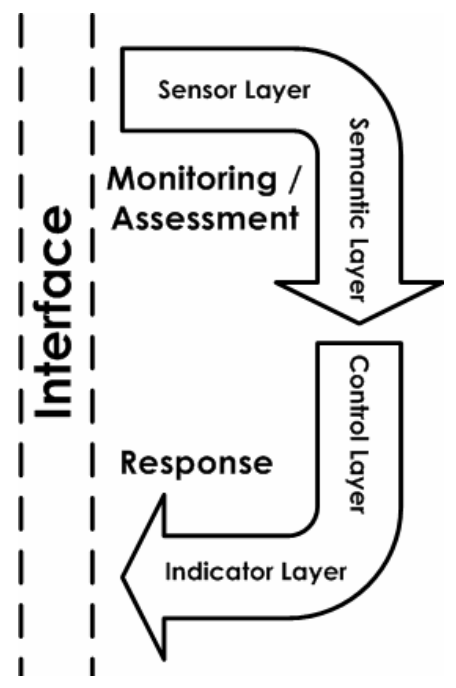


The sensor layer is responsible for capturing the interaction footprints. A sensor is a simple measuring unit for a single type of data. Although the objective of sensor layer is to trace user interactions, it may also include other measures that are relevant for the learning process, but they are not a direct result of an interaction of a learner with the environment. Such a sensor may capture tags, standardised meta-data, or peer ratings. This data is part of the interaction between the user and a system, but it is externally assigned to the content or the system. The scenario describes the outcomes of a contextual sensor that tracks the ratings of Tim's peers on his contributions.

The semantic layer collects the data from the sensors and aggregates them into higher level information. In terms of the scenario, 'activity' is defined by the operations or rules in the semantic layer (Cristea \& Calvi, 2003). The definition of how the data from one or more sensors has to be transformed is called an aggregator (Dey, 2000). These rules can be named according to their meaning. The aggregators in our scenario were named 'activity' and 'effort'.

The aggregated information is interpreted by the control layer according to the context of a learner. The specific approach for interpretation is called a strategy (Cristea \& Calvi, 2003). A strategy defines the conditions for selecting and combining aggregators and their presentation according to the context of the learner. A strategy also controls the personalisation of aggregators to the learner. In the scenario, the strategy adapts to the learning process according to the additional information that becomes available.

Finally, the aggregated information has to get presented to the user. The indicator layer handles the communication back to the learner. At this level the actual response is created by translating aggregated values into representations that are human readable. The active strategy of the control layer selects these representations and feeds aggregated information to them. That way the representations follow the strategies, which is in alignment of our second requirement.

For this review we will apply these four layers to analyse the literature, because the model meets the four principles of external feedback:

- Monitoring is facilitated by the sensor and the semantic layer of the model. The sensor layer collects footprints of the learning interactions. The semantic layer clusters and organises the data provided by the different sensors in order to make it accessible for presentation or further processing.

- Adaptation to the learner's goals, actions, performance, outcomes, history and learning context is handled by the strategies of the control layer. Depending on those strategies the results of the semantic layer selects parts of that information for indicating them to the learner. The control layer uses strategies to select aggregators that are appropriate to a learner's situation. A strategy in the control layer may also adapt timing and style of an indication.

- Each indicated information is a response on the learners' actions or on the context of the learning process because it results from a monitoring process. Indicating the results back to the learner is managed by the indicator layer. It transforms the information that is provided by the underlying layers regarding the interface that is used by the learner.

We apply this model to analyse the existing research systematically. According to the four layers of the model, the literature is reviewed on the sensors, aggregators, strategies, 
and indicators that were applied. In a second step, we focus on the reported effects on the learning process.

\section{Current perception of the learning interaction support}

In this section we report on four different research perspectives of indicating information that is relevant for a learning process. These research perspectives are:

- Approaches from the domain of adaptive hypermedia (Ahn, Brusilovsky, \& Farzan, 2005; Bretzke \& Vassileva, 2003; Cheng \& Vassileva, 2005a, 2005b; Farzan \& Brusilovsky, 2005; Vassileva, 2004).

- Solutions for social awareness web- and collaborative environments (Ellis \& Dix, 2004; Kreijns, 2004; Kreijns \& Kirschner, 2002; Mealha, Sousa Santos, Nunes, \& Zamfir, 2004).

- $\quad$ Recommendation systems (Klerkx, Duval, \& Meire, 2004; Ng \& Martin, 2004; Nguyen, Huang, \& Hawryszkiewycz, 2004)

- Approaches that focussed only on contextual information without taking any user interaction footprints into account (Gatalsky, Andrienko, \& Andrienko, 2004).

In this review we do not consider solutions that focus entirely on social interaction, such as chat or instant messaging as it was reported by Erickson and his colleagues (e.g. Ding et al., 2007; Erickson et al., 1999). Also, this review does not cover approaches of the use of mobile devices in education, or ubiquitous interactions in smart places.

The selection criteria for the literature were that the reported approaches utilize graphical indicators to display information that are relevant to learners. All approaches are analysed according to the layers of the model that we introduced in the previous section.

We found a wide range of approaches that utilise sensors, aggregators, strategies and indicators for different purposes. In general, most work applies one strategy that is based on a fixed set of sensors and just a single aggregator (Cheng \& Vassileva, 2005a, 2005b; Ellis \& Dix, 2004; Farzan \& Brusilovsky, 2005; Marcos, Martinez, Dimitriadis, \& Anguita, 2006; Mealha, Sousa Santos, Nunes, \& Zamfir, 2004; Ng \& Martin, 2004). Also it appears that the problem is partly recognised as a problem of information visualisation.

\section{Sensors to monitor user interaction}

At the input level of the analytical model is the sensor layer. Sensors capture interaction footprints and make them available for further processing. At this level the literature was analysed regarding to the sources used in the interaction process. We identified four main sensor groups. The sensors within each group vary on the actual data they capture, but share common characteristics. The four sensor groups are:

- $\quad$ Time sensors cover all timing measures, such as timestamps or durations;

- Social context sensors track of the interaction behaviour of the peers of a user; 
- User sensors monitor the interactions of a single user;

- Environment sensors collect data about the context of a learner.

Time sensors cover concepts such as timestamps, for instance the event time (Gatalsky, Andrienko, \& Andrienko, 2004), such as page accesses (Ellis \& Dix, 2004; Greer et al., 1998) or document manipulation (Kreijns, 2004; Kreijns \& Kirschner, 2002); durations, or more precisely the time spent reading a document (Farzan \& Brusilovsky, 2005); and time intervals such as the beginning and the end of user sessions (Mealha, Sousa Santos, Nunes, \& Zamfir, 2004).

Social context sensors refer to all measures of the interaction behaviour related to the peers of the user who is the target of the response. Social context sensors are not used to indicate the collected data for each user, but are aggregated for a group of users (Farzan \& Brusilovsky, 2005; Kreijns, 2004). These sensors include information access (Bretzke \& Vassileva, 2003; Cheng \& Vassileva, 2005a, 2005b; Ellis \& Dix, 2004; Farzan \& Brusilovsky, 2005; Mealha, Sousa Santos, Nunes, \& Zamfir, 2004); number of contributions such as documents and forum posts; (Cheng \& Vassileva, 2005a, 2005b); peer ratings, comments and reviews (Bretzke \& Vassileva, 2003; Cheng \& Vassileva, 2005a; Greer et al., 1998; Ng \& Martin, 2004); search terms used (Bretzke \& Vassileva, 2003; Klerkx, Duval, \& Meire, 2004); connection to other peers (Bretzke \& Vassileva, 2003; Marcos, Martinez, Dimitriadis, \& Anguita, 2006); self assessment (Greer et al., 1998); or the number of time a task has been conducted by a user (Greer et al., 1998). These sensors collect information about the social context of a learner.

User Sensors cover those sensors that measure the interaction of the user who will receive the response. In principal, these sensors are the same as social context sensors. The main difference is that these sensors capture data directly from the learner for whom the information will be aggregated. Claypool, Le, Wased, \& Brown (2001) analysed and validated a set of sensors (which the authors call indicators) according to the reliability and validity of these sensors for measuring a user's interest and attention. From that study five groups of user sensors are applicable for this review:

- Explicit interest sensors like sensors that capture for example the text a user has typed into a query form.

- Marking interest sensors are for example sensors that track the ratings about the quality of a document.

- Manipulation interest sensors such as sensors that recognise if a user has created or changed an object.

- Navigation interest sensors like sensors that track which links a user follows.

- External interest sensors that track the keywords of a learning object's meta-data, for instance.

Environment sensors are those sensors that collect data about the context of a learner. These sensors may capture spatial information (Greer et al., 1998), learning object metadata (Farzan \& Brusilovsky, 2005; Klerkx, Duval, \& Meire, 2004; Mealha, Sousa Santos, Nunes, \& Zamfir, 2004; Nguyen, Huang, \& Hawryszkiewycz, 2004), and hyper-link structures (Gatalsky, Andrienko, \& Andrienko, 2004; Nguyen, Huang, \& Hawryszkiewycz, 2004). 
Our review indicated that time and social context sensors play an important role in the reviewed literature (see Figure 3). These types of sensors are heavily used in higher level aggregators.

Figure 3 Sensor usage reported by the literature, ordered by origin

\begin{tabular}{|c|c|c|c|c|}
\hline & User & Social Context & Environment & Time \\
\hline $\begin{array}{l}\text { Ahn, Brusilovsky, \& } \\
\text { Farzan, } 2005\end{array}$ & $\begin{array}{l}\text { Requested pages; } \\
\text { goal definition }\end{array}$ & $\begin{array}{l}\text { Requested pages; } \\
\text { annotation; ratings }\end{array}$ & \begin{tabular}{|l|} 
Keywords; \\
content meta- \\
data
\end{tabular} & \\
\hline $\begin{array}{l}\text { Bretzke \& Vassileva, } \\
2003\end{array}$ & & $\begin{array}{l}\text { Requested pages; } \\
\text { ratings; contributions; } \\
\text { annotations; peer } \\
\text { relations; used search } \\
\text { terms }\end{array}$ & & \\
\hline $\begin{array}{l}\text { Cheng \& Vassileva, } \\
\text { 2005b; Vassileva, } \\
2004\end{array}$ & & $\begin{array}{l}\text { Requested pages; } \\
\text { ratings; contributions; } \\
\text { annotation }\end{array}$ & & $\begin{array}{l}\text { Interval } \\
\text { (Online Time) }\end{array}$ \\
\hline $\begin{array}{l}\text { Cheng \& Vassileva, } \\
\text { 2005a }\end{array}$ & \begin{tabular}{|l|} 
Forum \\
contributions
\end{tabular} & $\begin{array}{l}\text { Forum postings; } \\
\text { ratings }\end{array}$ & & \\
\hline Ellis \& Dix, 2004 & & Requested pages & & $\begin{array}{l}\text { Time stamp of } \\
\text { page access }\end{array}$ \\
\hline \begin{tabular}{|l} 
Farzan \& \\
Brusilovsky, 2005
\end{tabular} & & Requested pages & $\begin{array}{l}\text { Content } \\
\text { meta-data }\end{array}$ & $\begin{array}{l}\text { Duration } \\
\text { (reading Time) }\end{array}$ \\
\hline $\begin{array}{l}\text { Gatalsky, Andrienko, } \\
\text { \& Andrienko, } 2004\end{array}$ & & & $\begin{array}{l}\text { Geographical } \\
\text { position; } \\
\text { related events }\end{array}$ & Event time \\
\hline Greer et al., 1998 & $\begin{array}{l}\text { Self recognition } \\
\text { questionnaire; } \\
\text { times of task } \\
\text { completion }\end{array}$ & Ratings & & $\begin{array}{l}\text { Action time } \\
\text { stamp }\end{array}$ \\
\hline $\begin{array}{l}\text { Kreijns, 2004; } \\
\text { Kreijns \& Kirschner, } \\
2002\end{array}$ & Action counter & $\begin{array}{l}\text { Action counter; peer } \\
\text { notifications }\end{array}$ & & $\begin{array}{l}\text { Action time } \\
\text { stamp }\end{array}$ \\
\hline $\begin{array}{l}\text { Klerkx, Duval, \& } \\
\text { Meire, } 2004\end{array}$ & $\begin{array}{l}\text { Document } \\
\text { selection; search } \\
\text { query }\end{array}$ & & $\begin{array}{l}\text { LOM Data- } \\
\text { sets; DRM } \\
\text { privileges; }\end{array}$ & \\
\hline $\begin{array}{l}\text { Marcos, Martinez, } \\
\text { Dimitriadis, \& } \\
\text { Anguita, } 2006\end{array}$ & Contributions & $\begin{array}{l}\text { Contributions; rating; } \\
\text { relations }\end{array}$ & & \\
\hline $\begin{array}{l}\text { Mealha, Sousa } \\
\text { Santos, Nunes, \& } \\
\text { Zamfir, } 2004\end{array}$ & Session identifier & & $\begin{array}{l}\text { Content } \\
\text { meta-data; } \\
\text { link structure }\end{array}$ & $\begin{array}{l}\text { Duration } \\
\text { (reading time) }\end{array}$ \\
\hline $\begin{array}{l}\text { Nguyen, Huang, \& } \\
\text { Hawryszkiewycz, } \\
2004\end{array}$ & & & $\begin{array}{l}\text { Content } \\
\text { meta-data; } \\
\text { link structure }\end{array}$ & \\
\hline Ng \& Martin, 2004 & $\begin{array}{l}\text { Document } \\
\text { selection }\end{array}$ & Rating & $\begin{array}{l}\text { Content } \\
\text { meta-data }\end{array}$ & \\
\hline
\end{tabular}


Although user sensors were also mentioned, they are mostly used to select peer user and context information. In combination with social context sensors the user sensors generate the learning history. This interaction history is then used to bias the data from peer user sensors (Cheng \& Vassileva, 2005a, 2005b; Greer et al., 1998). In combination with environmental sensors, actual user sensors refer to previous or current selections or search terms that are used by a learner (Klerkx, Duval, \& Meire, 2004; Mealha, Sousa Santos, Nunes, \& Zamfir, 2004). Only Kreijns (2004) describes an indicator that is entirely based on actual user sensors.

Although we could identify a range of sensor combinations, we also found that a group of sensors is particularly popular (see Figure 3). Among time sensors the event time (including time stamps of page accesses) was mentioned four times (Ellis \& Dix, 2004; Gatalsky, Andrienko, \& Andrienko, 2004; Greer et al., 1998; Kreijns, 2004). Regarding the social context sensors peer ratings (Ahn, Brusilovsky, \& Farzan, 2005; Bretzke \& Vassileva, 2003; Cheng \& Vassileva, 2005a, 2005b; Greer et al., 1998; Marcos, Martinez, Dimitriadis, \& Anguita, 2006; Ng \& Martin, 2004) and the requested pages (Ahn, Brusilovsky, \& Farzan, 2005; Bretzke \& Vassileva, 2003; Cheng \& Vassileva, 2005b; Ellis \& Dix, 2004; Farzan \& Brusilovsky, 2005) are mostly applied. Content meta-data is a popular environmental sensor (Ahn, Brusilovsky, \& Farzan, 2005; Farzan \& Brusilovsky, 2005; Klerkx, Duval, \& Meire, 2004; Mealha, Sousa Santos, Nunes, \& Zamfir, 2004; Ng \& Martin, 2004; Nguyen, Huang, \& Hawryszkiewycz, 2004). Contributions are used for gathering information about both the user and social context (Bretzke \& Vassileva, 2003; Cheng \& Vassileva, 2005b; Marcos, Martinez, Dimitriadis, \& Anguita, 2006).

\section{Meaningful information through semantic aggregators}

On the levels of the semantic and the control layer we found a great number of approaches. Our review showed that the approaches found on each layer are closely related to the goals of the overall application. Therefore, interoperability between systems and transferring a solution to other domains or data sources was not considered by the literature under review.

We found that in the majority of the research a single aggregator and a single strategy is used (see Figure 4). Only few researches were interested in multiple semantic aggregators. In these cases personalisation, in terms of control strategies, is of no interest (Gatalsky, Andrienko, \& Andrienko, 2004; Klerkx, Duval, \& Meire, 2004) or is conducted by applying user profile filters to the information from the semantic layer (Bretzke \& Vassileva, 2003).

In the literature we found basically three types of semantic aggregators:

- Simple arithmetic aggregators

- Naïve statistic aggregators

- Network aggregators

Simple arithmetic aggregators cover all approaches that include only basic arithmetic operations, such as sum (Bretzke \& Vassileva, 2003; Ellis \& Dix, 2004; Farzan \& Brusilovsky, 2005; Kreijns, 2004; Kreijns \& Kirschner, 2002), enumeration (Greer et al., 1998; Mealha, Sousa Santos, Nunes, \& Zamfir, 2004) and equity (Nguyen, Huang, \& 
Hawryszkiewycz, 2004).

Figure 4 Types of semantic aggregators and control strategies

\begin{tabular}{|l|l|l|}
\hline & Semantic aggregator & Control strategy \\
\hline Ahn, Brusilovsky, \& Farzan, 2005 & Multiple & Single \\
\hline Bretzke \& Vassileva, 2003 & Multiple & Single \\
\hline Cheng \& Vassileva, 2005b; Vassileva, 2004 & Single & Single \\
\hline Cheng \& Vassileva, 2005a & Single & Single \\
\hline Ellis \& Dix, 2004 & Single & Single \\
\hline Farzan \& Brusilovsky, 2005 & Single & Single \\
\hline Gatalsky, Andrienko, \& Andrienko, 2004 & Multiple & N/A \\
\hline Greer et al., 1998 & Single & Multiple \\
\hline Kreijns, 2004; Kreijns \& Kirschner, 2002 & Multiple & N/A \\
\hline Klerkx, Duval, \& Meire, 2004 & Multiple & N/A \\
\hline Marcos, Martinez, Dimitriadis, \& Anguita, 2006 & Single & Single \\
\hline Mealha, Sousa Santos, Nunes, \& Zamfir, 2004 & Single & Single \\
\hline Nguyen, Huang, \& Hawryszkiewycz, 2004 & N/A & Single \\
\hline Ng \& Martin, 2004 & Single & Single \\
\hline
\end{tabular}

Naïve statistics refer to those approaches that aggregate the sensor data with a simple statistical function like the arithmetic mean (Cheng \& Vassileva, 2005a; Ng \& Martin, 2004).

Network aggregators analyse relations between learners and information. We identified aggregators analysing social relations within a learning network (Ahn, Brusilovsky, \& Farzan, 2005; Bretzke \& Vassileva, 2003; Cheng \& Vassileva, 2005b; Marcos, Martinez, Dimitriadis, \& Anguita, 2006). These approaches provide information on the context of the learner. Other approaches make use of environmental relations (Gatalsky, Andrienko, \& Andrienko, 2004; Klerkx, Duval, \& Meire, 2004). In such cases the information of a system is organised according to a user's selection or profile. This helps learners to understand the structure of an information space while they explore it.

\section{Control strategies for adaptation}

For the control layer we found no approaches that dynamically adapt the control strategy according to the learner's prior activities. In those cases where multiple control strategies were identified, the approaches were concurrently available to the users. Nonetheless, we were able to identify three different groups of control strategies:

- $\quad$ Null strategies select information from the semantic layer according to the users preferences. The data from the semantic layer is not further processed.

Personalisation means at this level that if information is accessible or not, depends on a learner's profile. The null strategies include those approaches that do not personalise the information at all. Null strategies are applied in social awareness 
systems (Kreijns, 2004; Kreijns \& Kirschner, 2002; Marcos, Martinez, Dimitriadis, \& Anguita, 2006) and navigation support for content repositories or databases (Gatalsky, Andrienko, \& Andrienko, 2004; Klerkx, Duval, \& Meire, 2004).

- Clustering strategies organise the information from the semantic layer into clusters or groups. Clustering organises the similar information according to the learner's profile. The clustering process includes reorganising the information before it is passed to the indicator layer. This approach is used in content recommendation systems (Ellis \& Dix, 2004; Farzan \& Brusilovsky, 2005) but also for navigation support in content repositories (Nguyen, Huang, \& Hawryszkiewycz, 2004).

- Scoring and sorting strategies create an order between sensor measures, users or contents. This approach is of a higher level than clustering, because it reflects the order between elements during the clustering process. This approach is used in content recommendation systems (Mealha, Sousa Santos, Nunes, \& Zamfir, 2004; Ng \& Martin, 2004) as well as in collaboration support (Bretzke \& Vassileva, 2003; Cheng \& Vassileva, 2005a, 2005b).

\section{Indicator Types}

The indicators are those parts of the responding system that present the interaction footprints to the learners. Therefore, they often depend directly on the system in which they are used. We identified four groups of indicators:

When embedded content indicators are used, the information indicator is embedded in the content structure. This includes modified backgrounds, highlighted content and coloured links (Farzan \& Brusilovsky, 2005).

$1 D$-graphical indicators include all indicators that present information graphically. This includes approaches such as status indicators that use colour encodings to indicate the level of a user in the system (Bretzke \& Vassileva, 2003; Cheng \& Vassileva, 2005a, 2005b); Rating indicators (Cheng \& Vassileva, 2005b); or progress bars and counters (Bretzke \& Vassileva, 2003; Ng \& Martin, 2004).

$2 D$-graphical indicators help display relations between information in 2D space. This can be relations of complex hierarchical data such as it can be found for content repositories (Klerkx, Duval, \& Meire, 2004); computer supported collaborative work (CSCW) (Marcos, Martinez, Dimitriadis, \& Anguita, 2006); or social interaction patterns on a web site (Ellis \& Dix, 2004; Nguyen, Huang, \& Hawryszkiewycz, 2004)

If very complex information has to get reported to the learner, $3 D$ graphical indicators can be used. These indicators display complex structures (Mealha, Sousa Santos, Nunes, \& Zamfir, 2004) or different information dimensions in a 3D space (Gatalsky, Andrienko, \& Andrienko, 2004).

\section{Validity of the reported approaches}

One result of the review is that not all of the reported aggregators and strategies are based on empirically validated concepts. On one hand this indicates explorative research and the need of further empirical work. On the other hand, it is difficult to validate an approach or to explain the origin of effects on the learning process. For this reason we 
analysed the validity of those approaches that are discussed in this review. We assumed validity of an approach on one layer, if other research has been quoted, which had successfully applied the approach and/ or found similar effects. Figure 5 shows which parts of the approaches are based on previously validated concepts.

We did not analyse the underlying models on internal and statistical validity or on predictability, because the reviewed literature does not provide sufficient information for this task.

Figure 5 Components that are grounded in research

\begin{tabular}{|c|c|c|c|c|}
\hline & Sensor layer & Semantic layer & Control layer & Indicator layer \\
\hline $\begin{array}{l}\text { Ahn, Brusilovsky, \& } \\
\text { Farzan, } 2005\end{array}$ & OK & - & - & OK \\
\hline Bretzke \& Vassileva, 2003 & - & - & - & OK \\
\hline $\begin{array}{l}\text { Cheng \& Vassileva, } \\
\text { 2005b; Vassileva, } 2004\end{array}$ & - & (OK) & OK & OK \\
\hline Cheng \& Vassileva, 2005a & OK & - & - & OK \\
\hline Ellis \& Dix, 2004 & OK & OK & - & OK \\
\hline $\begin{array}{l}\text { Farzan \& Brusilovsky, } \\
2005\end{array}$ & OK & - & - & OK \\
\hline $\begin{array}{l}\text { Gatalsky, Andrienko, \& } \\
\text { Andrienko, } 2004\end{array}$ & OK & OK & N/A & OK \\
\hline Greer et al., 1998 & OK & - & - & - \\
\hline $\begin{array}{l}\text { Kreijns, 2004; Kreijns \& } \\
\text { Kirschner, } 2002\end{array}$ & - & - & N/A & OK \\
\hline $\begin{array}{l}\text { Klerkx, Duval, \& Meire, } \\
2004\end{array}$ & OK & - & N/A & OK \\
\hline $\begin{array}{l}\text { Marcos, Martinez, } \\
\text { Dimitriadis, \& Anguita, } \\
2006\end{array}$ & OK & - & - & OK \\
\hline $\begin{array}{l}\text { Mealha, Sousa Santos, } \\
\text { Nunes, \& Zamfir, } 2004\end{array}$ & OK & OK & - & OK \\
\hline $\begin{array}{l}\text { Nguyen, Huang, \& } \\
\text { Hawryszkiewycz, } 2004\end{array}$ & OK & - & - & OK \\
\hline Ng \& Martin, 2004 & OK & - & - & - \\
\hline
\end{tabular}

Although most authors refer to other research with regard to the sensors they have applied, these references regularly don't provide empirical validity on the sensor. Only Farzan \& Brusilovsky (2005) argue the selection of the sensors on the base of a correlation between the sensors and the information that should be aggregated from them.

Most authors define aggregators and conditions of using them in a scenario, but only a few authors specify their aggregators precisely (Ahn, Brusilovsky, \& Farzan, 2005; Cheng \& Vassileva, 2005a, 2005b; Farzan \& Brusilovsky, 2005). These aggregator definitions are sound, but lack of empirical evidence regarding their relevance for the learning process. This may lead to wrong expectations and even disappointment of the learners (Farzan \& Brusilovsky, 2005). 
Although, most authors mention a strategy for their approach, no one provided a specification for it. Only for one approach the authors base the use of the strategy on external references (Cheng \& Vassileva, 2005b; Vassileva, 2004). The reason for this could be the tight relation between the strategy and the indicator as it was found in many approaches.

Almost all approaches adopted an indicator that has been successfully implemented elsewhere. Where the indicators where entirely graphical, the indicators have been developed in the field of information visualisation (Ellis \& Dix, 2004; Gatalsky, Andrienko, \& Andrienko, 2004; Klerkx, Duval, \& Meire, 2004; Mealha, Sousa Santos, Nunes, \& Zamfir, 2004; Nguyen, Huang, \& Hawryszkiewycz, 2004). These approaches have in common that they refer neither to usability nor to educational research to argue the use of an indicator. The reason for this can be that these aspects were not the primary focus to that research. Where the indicator had a clear educational purpose, the use of the indicator was also grounded in that field (Bretzke \& Vassileva, 2003; Cheng \& Vassileva, 2005a, 2005b; Kreijns, 2004; Kreijns \& Kirschner, 2002; Vassileva, 2004). Embedding the indicator into the content structure of the learning environment is an alternative approach of applying indicators (Ahn, Brusilovsky, \& Farzan, 2005; Farzan \& Brusilovsky, 2005). Such approaches appear useful if the indicator helps the learner to navigate through the content. Therefore, it is not surprising that the use of these indicators is grounded in the research of adaptive hypermedia.

\section{Effects on the learning interaction cycle}

A large number of the analysed approaches did not report effects of indicating information on the learning interaction cycle, but describe the technology and possible solutions. Nevertheless, some effects on the learning interaction cycle were found by empirical evaluation and reported (Cheng \& Vassileva, 2005b; Farzan \& Brusilovsky, 2005; Kreijns, 2004; Marcos, Martinez, Dimitriadis, \& Anguita, 2006).

Cheng \& Vassileva (2005b) were able to successfully stimulate learner contributions to the learning environment through the additional indicator. In this case the strategy implemented a rewarding mechanism. The users became aware of this rewarding mechanism and set strategic goals according to it. As a side effect, the authors reported a decrease in the quality of the contributions.

Farzan \& Brusilovsky (2005) reported that learners participated more continuously to a course if the indicator was provided. The findings show that the non-rewarding mechanism helped learners to identify and use high-quality material in a content repository. However, the authors assume that the positive effects were constrained because the actual decision of which contents to use was to the learner.

Marcos, Martinez, Dimitriadis, \& Anguita (2006) found positive effects of providing graphical indicators. This includes higher commitment and more contributions in collaborative activities.

Kreijns (2004) reports that learners felt more aware about their presence in a virtual learning environment, when they received graphical responses (Kreijns, 2004, p. 190). However, the author also detected that the provided graphical group awareness tool encouraged spying among peers. Kreijns concludes that graphical representations should provide suggestions of their usage, in order to avoid false expectations or misuse. 


\section{Conclusions and questions of further research}

This paper focused on the relevant information for collecting and presenting contextual information, its effects and impact on the learning interaction cycle, and mechanisms of controlling it. The core principle of the learning interaction cycle is the interaction of learners with their learning environment. Previous research highlights that such interaction is important for the experience and progress of learners. However, we identified a conceptual gap between the learner actions within a learning environment and the responses that are provided to the learners. To bridge this gap we adopted a layered model of context-aware systems that meets the requirements for supportive responses as they were defined by Ley \& Young (2001). The model has four layers and describes the information processing of interaction footprints of learners in a learning environment: The sensor layer, the semantic layer, the control layer, and the indicator layer. We applied this model to analyse the results as they were reported in the literature.

It is remarkable that in the reviewed literature, the sensors and indicators where grounded on existing research, while this was not always confirmed for aggregators and strategies. Also, most studies reported on combinations of a single approach each on the semantic and the control layer. It appears like the factors of generating responses to a learner are on an experimental stage. This is confirmed by the reported effects of indicators on the learning process.

We did not identify cases or experimental studies that are similar to the scenario that has been described earlier in this paper. In other words we were not able to find hard evidence whether or not "smart indicators" have a positive impact on the learning interaction cycle and on the learning process. This leads us to fundamental questions for further research:

What contextual information is relevant to support the learning process and does this information change throughout the individual learning process?

This question addresses the problem of the learning interaction cycle at large. It addresses the way how to provide meaningful responses to learners, as it has been reported in the literature. From a more technological perspective, this question can be rephrased as:

How can a system collect data and aggregate contextual information in a way that it can provide meaningful information in the different stages of a learning process?

A second question addresses the effects of indicators on the learning process. The literature does not provide clear evidence of positive effects of using indicators in the learning process. It appears that the even similar approaches result in different effects. Therefore are answers to the following question essential for providing 'smart indicators':

What is the effect of different aggregators, strategies and indicators on the learning process and how can they effectively combined and applied for supporting the learning process?

Although, the review of the literature provided several approaches to supporting learners, the answers to these questions remained unspecific. In our further research we have planned to implement an application that is based on the model. This application is then used to address these research questions empirically. 


\section{Acknowledgements}

This paper is (partly) sponsored by the TENCompetence Integrated Project that is funded by the European Commission's $6^{\text {th }}$ Framework Programme, priority IST/Technology Enhanced Learning. Contract 027087 (www.tencompetence.org).

\section{References}

Ahn, J.-w., Brusilovsky, P., \& Farzan, R. (2005). A Two-Level Adaptive Visualisation for Information Access to Open-Corpus Resources. Paper presented at the International Conference on User Modeling (UM'05), Edinburgh, U.K.

Beck, J. C., \& Wade, M. (2004). Got Game: how the gamer generation is reshaping business forever. Boston, MA: Harvard Business School Press.

Beenen, G., Ling, K., Wang, X., Chang, K., Frankowsky, D., Resnick, P., et al. (2004). Using social psychology to motivate contributions to online communities. Paper presented at the ACM conference on computer supported cooperative work (CSCW 2004), Chicago, Illinois.

Bretzke, H., \& Vassileva, J. (2003). Motivating cooperation on peer to peer networks. Paper presented at the 9th International Conference on User Modeling (UM'03).

Butler, D. L., \& Winne, P. H. (1995). Feedback and self-regulated learning: a theoretical synthesis. Review of Educational Research, 65(3), 245-281.

Cheng, R., \& Vassileva, J. (2005a). Adaptive rewarding mechanism for sustainable online learning community. Paper presented at the 12th International Conference on Artificial Intelligence in Education (AIED'05), Amsterdam.

Cheng, R., \& Vassileva, J. (2005b). User motivation and persuation strategy for peer-to-peer communities. Paper presented at the 38th Hawaii International Conference on System Sciences (HICSS'05), Hawaii, United States.

Claypool, M., Le, P., Wased, M., \& Brown, D. (2001). Inplicit Interest Indicators. Paper presented at the ACM Intelligent User Interfaces Conference (IUI 2001), Santa Fe, New Mexico.

Cristea, A., \& Calvi, L. (2003). The three layers of adaptation granularity. Paper presented at the 9th International Conference on User Modelling 2003, Johnstown, PA, United States.

Dey, A. K. (2000). Enabling the use of context in interactive applications. Paper presented at the Computer-Human Interaction de Hague, NL.

Dey, A. K. (2001). Understanding and using context. Personal and Ubiquitous Computing, 5(1), 47.

Dey, A. K., \& Abowd, G. D. (2000). Towards a Better Understanding of Context and ContextAwareness. Paper presented at the CHI 2000 Workshop on the What, Who, Where, When, and How of Context-Awareness.

Dey, A. K., Abowd, G. D., \& Salber, D. (1999). A Context-based Infrastructure for Smart Environments. Paper presented at the 1st International Workshop on Managing Interactions in Smart Environments (MANSE '99), Dublin, Ireland.

Dieberger, A. (1997). Supporting social navigation on the world wide web. International Journal of Human-Computer Studies, 46(6), 805-825.

Ding, X., Erickson, T., Kellogg, W. A., Levy, S., Christiensen, J. E., Sussmann, J., et al. (2007). An empirical study of the use of visually enhanced VoIP audio conferencing: the case of IEAC. Paper presented at the Computer/Human Interaction (CHI2007), San Jose, CA, United States.

Dron, J., Boyne, C., \& Mitchell, R. (2001). Footpaths in the the stuff swamp. Paper presented at the World Conferences on the WWW and Internet, Orlando, Florida, United States.

Ellis, G., \& Dix, A. (2004). Visualising web visitations: a probabilistic approach. Paper presented at the 8th International Conference on Information Visualisation (IV'04). 
Erickson, T., Smith, D. N., Kellogg, W. A., Laff, M., Richards, J. T., \& Brandner, E. (1999). Socially translucent systems: social proxies, persistent conversation, and the design of "Babble". Paper presented at the Human Factors in Computing Systems (CHI'99).

Farzan, R., \& Brusilovsky, P. (2005). Social navigation support in e-learning: what are the real footprints? Paper presented at the Intelligent Techniques for Web Personalisation (ITWP'05), Edinburgh, Scotland.

Garries, R., Ahlers, R., \& Driskel, J. E. (2002). Games, motivation, and learning: a research and practice model. Simulation \& Gaming, 33(4), 441-467.

Gatalsky, P., Andrienko, N., \& Andrienko, G. (2004). Interactive analysis of event data using space-time cube. Paper presented at the 8th International Conference on Information visualisation (IV'04).

Greer, J., McCalla, G., Collins, J., Kumar, V., Meagher, P., \& Vassileva, J. (1998). Supporting peer help and collaboration in distributed workplace environments. International Journal of Artificial Intelligence in Education (IJAIED), 9, 159-177.

Illeris, K. (2003). Learning changes throughout life. Lifelong Learning in Europe, 8(1), 51-60.

Jamieson-Noel, D., Chu, S. T. L., \& Winne, P. H. (2004). The effect of feedback on calibration of study tactics and performance. Paper presented at the American Educational Resaerch Association (AERA), San Diego, CA.

Klerkx, J., Duval, E., \& Meire, M. (2004). Using information visualisation for accessing learning object repositories. Paper presented at the Eighth International Conference on Information Visualisation (IV'04)

Kreijns, K. (2004). Socialble CSCL Environments; Social Affordances, Sociability, and Social Presence. Open University of the Netherlands, Heerlen, The Netherlands.

Kreijns, K., \& Kirschner, P. A. (2002). Group Awareness Widgets for Enhancing Social Interaction in Computer-supported Collaborative Learning Environments: Design and Implementation. Paper presented at the $32^{\text {nd }}$ ASEE/IEEE Frontiers in Education Conference, Boston, MA.

Ley, K., \& Young, D. B. (2001). Instructional principles for self-regulation. Educational Technology Research and Development, 49(2), 93-103.

Ling, K., Beenen, G., Luford, P., Wang, X., Chang, K., Li, X., et al. (2005). Using social psychology to motivate contributions to online communities. Journal of Computer-Mediated Communication, 10(4), article 10.

Marcos, J. A., Martinez, A., Dimitriadis, Y., \& Anguita, R. (2006). Apapting interaction analysis to support evaluation and regulation: a case study. Paper presented at the Sixth International Conference on Advanced Learning Technologies (ICALT), Kerkrade.

Mealha, Ó., Sousa Santos, B., Nunes, J., \& Zamfir, F. (2004). Integrated visualisation schemes for an information and communication web log based management system. Paper presented at the 8th International Conference on Information Visualisation.

Mory, E. H. (2003). Feedback Research Revisited. In D. H. Jonassen (Ed.), Handbook of research for educational communications and technology: A Project of the Association for Educational Communications and Technology (pp. 745-784). New York: Macmillan.

Ng, C. U., \& Martin, G. R. (2004). Automatic selection of attributes by importance in relevance feedback visualisation. Paper presented at the 8th International Conference on Information Visualisation (IV'04).

Nguyen, Q. V., Huang, M. L., \& Hawryszkiewycz, I. (2004). A New Visualization Approach for Supporting Knowledge Management and Collaboration in E-Learning. Paper presented at the 8th International Conference on Information Visualisation (IV'04).

Orange, C. (1999). Using peer modelling to teach self-regulation. Journal of Experimental Education, 68(1), 21-40.

Rashid, A. M., Ling, K., Tassone, R. D., Resnick, P., Kraut, R. E., \& Riedl, J. (2006). Motivating participation by displaying the value of contribution. Paper presented at the Conference on human factors in computing systems (CHI 2006), Montreal, Quebeq, Canada. 
Schön, D. A. (1983). The Reflective Practitioner: How Professionals think in Action. London: Maurice Temple Smith.

Schön, D. A. (1987). Educating the Reflective Practitioner. San Francisco: Jossey-Bass.

Van Nimwegen, C., Van Oostendorp, H., Burgos, D., \& Koper, R. (2006). Does an interface with less assistance provoke more thoughtful behaviour? Paper presented at the Seventh International Conference of the Learning Sciences Bloomington, IN.

Vassileva, J. (2004). Harnessing p2p power in the classroom. Paper presented at the 7th International Conference on Intelligent Tutoring Systems (ITS 2004), Maceió, Alagoas, Brazil.

Weber, R. A. (2003). Learning and Transfer of Learning with No Feedback: An Experimental Test Across Games (No. 348).

Wexelblat, A., \& Maes, P. (1999). Footprints: history-rich tools for information foraging. Paper presented at the Conference on Human Factors in Computing Systems, Pittsburgh, Pennsylvania, United States.

Zimmermann, A., Specht, M., \& Lorenz, A. (2005). Personalisation and context management. User Modeling and User-Adapted Interaction, 15(3-4), 275-302. 